V.G. Zhekul, O.V. Khvoshchan, O.P. Smirnov, E.I. Taftaj, I.S. Shvets

\title{
ANALYSIS AND DEVELOPMENT OF THE BUBBLE MODEL OF THE FORMATION STAGE OF HIGH-VOLTAGE BREAKDOWN OF THE WATER GAP
}

\begin{abstract}
Purpose. A high-voltage underwater electric explosion, realized by discharging a capacitor into a water gap, is characterized by three main stages: the stage of formation of the plasma channel, the channel stage and post-discharge one. Substantially, the channel, post-discharge stages and the efficiency of energy release in the channel and the increase in the hydrodynamic effect on the object being processed depend on the parameters of the stage of formation. The purpose of the work was to review the existing mechanisms for the formation of a high-voltage discharge channel with the analysis and development of a bubble model of the stage of formation of water gap breakdown. Methodology. We have applied the analysis of existing theories on the formation of a high-voltage discharge channel, the carrying out of electrophysical studies with the processing of the obtained data. Results. A review and analysis of modern concepts of pre-breakdown processes in a high-voltage electric discharge in a liquid showed that the "bubble» model of the ignition of a discharge is applicable at an electric field strength $(36-180) \mathrm{kV} / \mathrm{cm}$. We have further developed the bubble model of the stage of formation of high-voltage breakdown on the results of experimental studies of the electrical characteristics of the discharge in the aqueous electrolyte with increased hydrostatic pressure and minimum voltage providing ignition of the discharge. A qualitative description of three phases of the stage of formation of the plasma channel in the liquid electrolyte is proposed. Originality. We have further developed the bubble model of the stage of formation of highvoltage breakdown of the liquid electrolyte on the results of experimental studies of the electrical characteristics of the discharge in the aqueous electrolyte with increased hydrostatic pressure and minimum voltage providing ignition of the discharge. A qualitative variation of the resistance of the gap in the pre-breakdown stage of the discharge is considered. Practical value. Determination of the scientific basis for creating a methodology for calculating the pre-breakdown characteristics of an electric discharge to improve the efficiency of electric discharge devices. References 19, figures 4.
\end{abstract}

Key words: high-voltage electric discharge, liquid electrolyte, oscillogram, pre-breakdown processes, bubble model.

Выполнен обзор и анализ современных представлений о предпробойных процессах при высоковольтном электрическом разряде в жсидкости. Показано, что «пузырьковая" («bиbble») модель зажигания разряда применима при напряженности электрического поля (36 - 180) кВ/см. По результатам экспериментальных исследований электрических характеристик разряда в водном электролите при повышенном гидростатическом давлении и минимальном напряжении, обеспечивающем зажигание разряда, получила дальнейшее развитие пузырьковая модель стадии формирования его высоковольтного пробоя. Предложено качественное описание трех фаз стадии формирования плазменного канала в жидком электролите. Библ. 19, рис. 4.

Ключевые слова: высоковольтный электрический разряд, жидкий электролит, осциллограмма, предпробойные процессы, пузырьковая модель.

Introduction. The development of electrohydraulic technologies in the second half of the twentieth century caused an increased interest in studying the characteristics of a pulsed electric discharge in liquids throughout the world. In the case of a high-voltage underwater electric explosion, realized by discharging a capacitor into a water gap [1], three main stages are selected:

1) the stage of formation of the plasma channel closing the interelectrode gap;

2) the channel stage, characterized by a sharp increase in the discharge current and the rapid release of electrical energy in the channel of high conductivity, which closes the opposite electrodes;

3) post-discharge stage - pulsation of the vapor-gas cavity after the end of the release of electrical energy in the discharge channel.

To a large extent, the channel and post-discharge stages, and, consequently, the efficiency of energy release in the channel and the increase in the impact on the object depend on the parameters of the stage of formation.

The goal of the work is a review of the existing mechanisms of the formation of a high-voltage discharge channel with the analysis and development of a bubble model of the stage of formation of water gap breakdown.

Basic definitions. Fig. 1 shows typical oscillograms of current and voltage for a high-voltage breakdown of a conducting liquid [2]. According to the oscillograms, the following parameters of the stage of formation of the current-carrying channel are determined:

- pre-leader time (discharge ignition time) $t_{d l}$ is the time from the moment of voltage application to the electrode system $U_{0}$ up to the moment of the beginning of the current increase corresponding to the instant of appearance of the plasma leader on one of the electrodes;

- leader time $t_{l}$ is the time from the moment when the current rises up to the beginning of a sharp decrease in the voltage $U_{0 a}$ and a simultaneous increase in the rate of current rise, which characterizes the onset of the channel stage of the discharge.

The pre-lieder stage corresponds to approximately constant current $i_{d l}$ and a slowly decreasing voltage $U_{d l}$, the slope of which is determined by the time constant of the storage discharge. The growth of the leader system at the leader stage leads to a decrease in the resistance of the gap, an increase in the current $i_{l}$ and a decrease in the voltage $U_{l}$. Under the ignition voltage of the discharge $U_{z}$ we mean the minimum voltage at which the plasma branch is formed on the electrode, and under the breakdown voltage the minimum voltage at which the discharge passes to the channel stage. The time of the prebreakdown stage of the formation of a conductive channel $t_{p p}$ is calculated by the formula:

$$
t_{p p}=t_{d l}+t_{l}
$$

(C) V.G. Zhekul, O.V. Khvoshchan, O.P. Smirnov, E.I. Taftaj, I.S. Shvets 


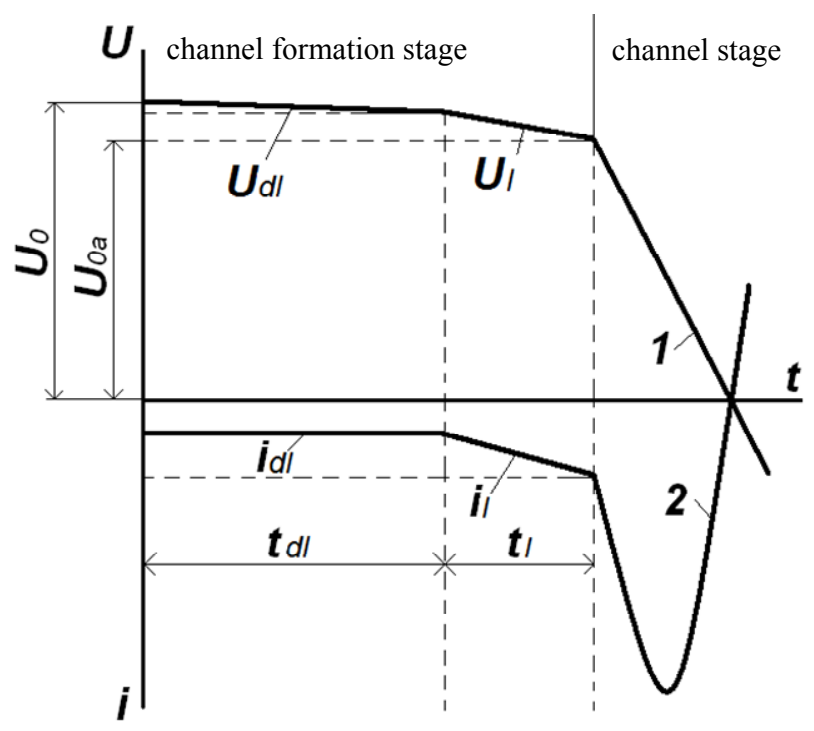

Fig. 1. Oscillograms of current and voltage in breakdown of conductive fluid: 1 - voltage $U ; 2$ - current $i$

A brief review of the concepts of pre-breakdown processes in a liquid. Immediately after applying voltage to the electrode system in the liquid, filling the interelectrode gap, processes that can lead, ultimately, to the formation of plasma branches begin. The influence of the field is accompanied by the appearance of currents, which can be registered with the help of special equipment. A further change in the electric field in the interelectrode gap will be observed due to a decrease in the voltage on the capacitor and phenomena occurring in the liquid itself when the field is applied.

The theory of the development of breakdown phenomena in liquids was originally based on the study of discharges in gases. In the thirties of the twentieth century, the Soviet scientist L.A. Yutkin received the first experimental results on the electro-hydraulic effect, and special attention was paid to processes at the high-voltage breakdown of liquids beginning in the second half of the twentieth century.

Initially, two groups of hypotheses about the mechanism of formation of a discharge in liquids were selected, depending on how they explain the appearance of charge carriers. The first group united hypotheses in which the process of discharge formation did not imply a violation of the phase homogeneity of the liquid. The second group provided for gas formation in a liquid and only then - ionization and breakdown. V.Ia. Ushakov combined the first group of mechanisms by the term electrical breakdown, the second one - by the electrothermal breakdown [3]. Electrical breakdown provides for the development of ionization processes in the liquid, and the electrothermal breakdown - the development of primary ionization processes in the gas phase after the boiling of the liquid.

Under the electrothermal initiation mechanism of the discharge, the author meant the following set of phenomena: the flow of the conduction current under the applied electric field, the heating of the liquid in the nearelectrode regions with the maximum field strength, the boiling of the liquid, the ionization of the vapor gas cavities, and the formation of the rudiment of the plasma channel. This mechanism can be realized for large values of the product of the specific electrical conductivity of a liquid on the duration of the voltage action. Since for pulse actions the duration of the voltage applied to the opposite electrodes does not usually exceed several hundred microseconds, such an initiation mechanism is likely in liquids with a high electrical conductivity, especially in electrolytes. The author considered the electrothermal initiation mechanism to be rare for pulsed breakdown of liquids.

I.P. Kuzhekin interpreted the mechanism of water breakdown with a specific electric conductivity of $2.5 \cdot 10^{-4} \mathrm{~S} / \mathrm{cm}$ by electrothermal [4] at field strengths at the tip electrodes $E=(8-36) \mathrm{kV} / \mathrm{cm}$. In hundreds thousands of microseconds from the moment of applying a voltage, near the tip a glow appears, the expansion of which leads to breakdown of the gap. At $E=(36-180) \mathrm{kV} / \mathrm{cm}$, the leader form of the discharge takes place, and the formation of the leaders is preceded by the luminescence of a high-voltage electrode. At $E>180 \mathrm{kV} / \mathrm{cm}$, the luminescence to the emergence of leaders is not observed. For small $E$, the movement of the leaders is a stepwise one, for large ones it is continuous.

Calculation of the dynamics of the formation of a gas bubble in water and its heating under the influence of the voltage applied to the electrodes by the electrothermal model at electric field strength up to $10 \mathrm{kV} / \mathrm{cm}$ is given in [5]. The use of a multiphysical calculation model in the COMSOL program showed that a discharge in water with a conductivity of $3 \mathrm{~S} / \mathrm{m}$ of a $5 \mathrm{mF}$ storage capacitance charged to a voltage of $3 \mathrm{kV}$ leads to an increase in the temperature in the interelectrode gap to (300-800) $\mathrm{K}$ and the transition of water to a vapor state.

The electrical breakdown mechanism was identified by V.Ia. Ushakov [3] by the absence of gas formation in the liquid before the appearance of luminescence, high speed of germination of the breakdown branch (up to $10^{5} \mathrm{~m} / \mathrm{s}$ and more), the absence of dependence of the electrical strength on the liquid temperature up to the boiling point and on the electrical conductivity of the liquid.

Considering the breakdown of low-conducting and dielectric liquids, the authors of [6] advance the idea of the significant role of emission, impact ionization, and autoionization of liquid molecules. In their opinion, autoionization occurs in the near-electrode layer of a liquid under the action of the field of the electrode surface microrelief. The strength of such a field can exceed by three orders of magnitude the average field strength in the gap, and the electrons arising during autoionization move to the anode, multiplying along the path due to impact ionization.

In [7], the effect of nanosecond voltage pulses on the breakdown of distilled water was studied with the justification of electrostriction as a factor in the development of optical density perturbations and rarefaction of water initiating the breakdown.

A brief review of the mechanisms of formation of streamer discharges in a liquid [8] mentions the influence of molecular ionization and ion dissociation factors, which depends on the electric field, Auger mechanism, accompanying the electric breakdown mechanism. 
The work [9] is devoted to the investigation of the electrical and hydrodynamic characteristics of the discharge in water at an elevated hydrodynamic pressure (up to $8 \mathrm{MPa}$ ). Here, the discharge of a capacitive storage device of60 $\mu \mathrm{F}$, charged to (8-13) $\mathrm{kV}$, was studied. The study showed that in the range $(0.1-4) \mathrm{MPa}$ in water there are gas bubbles that affect both the pre-breakdown characteristics of the discharge and the amplitude of the pressure wave excited by the discharge. In this case, in the range of up to $3 \mathrm{MPa}$, the amplitude of the pressure pulse increases with increasing hydrostatic pressure, and with a further increase in the hydrostatic pressure to $8 \mathrm{MPa}$, it decreases.

Thus, the researchers clearly determine the mechanism of formation of a discharge in a liquid by an electrothermal model (with electric field strength of up to $36 \mathrm{kV} / \mathrm{cm}$ ) and an electrical model (with a field strength above $180 \mathrm{kV} / \mathrm{cm}$ ). In the range of strengths limited by the indicated numerical values, the scientists proposed a «bubble» model of ignition of a discharge in a liquid.

«Bubble» model of ignition of the discharge. One of the first hypotheses about the mechanism of pulsed electric breakdown of water based on the «bubble» ignition model as part of the electrothermal model was put forward by E.V. Ianshin. The results of the studies [10] allowed the authors to conclude that the motion of electrons in a condensed medium will be accompanied by the release of energy in it in an amount that will ensure the shock boiling of the liquid and the formation of microbubbles, leading to a violation of the optical uniformity of the liquid. In these bubbles, ionization phenomena develop, which leads to the formation of a breakdown branch. E.V. Ianshin notes the possibility of the development of instabilities in this stage, associating with them a disordered structure of dendrites. After the breakdown of the gas micro-gap, the neighboring liquid layer boils up at the head of the germinated leader, then the process repeats.

Further development of the «bubble» model of the breakdown of polar and nonpolar dielectric liquids was obtained in the works of S.M. Korobeinikov [11]. According to the results of the experiment, under conditions of low hydrostatic pressure, bubbles can exist both near the electrodes and be formed with time after applying voltage to them due to microcavitation, local overheating of liquid and electrostrictive phenomena. The model of the processes leading to breakdown of the dielectric presupposed discharge in the bubble when the critical voltage reached on it, the deformation of the bubble by Coulomb forces, the field amplification in the region of the poles of the bubble, and the discharge into the liquid after reaching the critical field strength. On the basis of theoretical analysis, the author analytically obtained a particular solution for estimating the growth time of a bubble, which he relates to the pre-breakdown time when a stepwise voltage is applied.

According to the author's hypothesis [11], ionization processes (partial discharges) occur in it under the action of an electric field after reaching a certain value of the voltage drop (due to both bubble growth and the voltage applied to the electrodes) on the bubble. After discharge, the field in the bubble decreases due to shielding of the external field by the settled charges, which causes weakening or termination of the ionization processes. The action of the electric field on the settled charge leads to a stretching of the bubble along the field, and also to the progress of the charge into the interior of the liquid at a rate determined by the mobility of the charge carriers. In this case, two situations are possible: maintaining a discharge in the form of a glow discharge or stopping the discharge.

In the first case, a voltage is maintained on the bubble, apparently, consistent with Paschen law. In the latter case, the voltage on the bubble rises, which leads to a repeated discharge and the motion of a new wave of charges in the liquid. The determining parameter, the pressure on the bubble wall, is due to the action of Coulomb forces on the injected and surface charges and the increase in pressure in the bubble due to the heating of the gas in it. Ignition of a discharge in a liquid occurs when the field strength near the pole of the bubble reaches a critical value.

The author considered the criterion for the ignition of a discharge in a liquid to be a certain critical strength $E_{\max }=\left(10^{7}-10^{8}\right) \mathrm{V} / \mathrm{cm}$. The proposed bubble model allows, in the author's opinion, to calculate the prebreakdown time. However, the value of the field strength at which the breakdown of liquids occurs is determined by Martin formula:

$$
E_{b}=\frac{A}{t^{0.5} \cdot S^{0.1}},
$$

where $A$ is the constant depending on the type of liquid and the polarity of the initiating electrode, $t$ is the duration of applied voltage pulse, $S$ is the parameter that depends on the bare part of the electrode.

Investigations of breakdown of conducting nondegassed liquids, the results of which are given in [12], allowed the authors to conclude that in the range of the electrical conductivity of a liquid $\left.2 \cdot 10^{-5}-2 \cdot 10^{-3}\right) \mathrm{S} / \mathrm{cm}$ in the gaps $(3.5-13) \mathrm{cm}$ its breakdown in an inhomogeneous field is not associated with the preliminary formation of a continuous gas bridge even at times of several tens of microseconds. Gas bubbles are formed near the electrode or head of the discharge channel, and ionization of these bubbles contributes to the development of the discharge channel.

In [13], the processes of initiation and propagation of positive underwater streamers in water were studied using pulsed voltage with duration of $10 \mu \mathrm{s}$ based on the oscillography of the electrical characteristics of the discharge and shadow recording of the discharge development by an ultrahigh-speed camera. Thus, at field strength of $10 \mathrm{MW} / \mathrm{cm}$ at the tip electrode, clusters of microbubbles were observed near the electrode, within which microdischarges characterized by luminescence in the liquid occurred.

The above results indicate that scientists from many countries of the world have been engaged in researching the pre-breakdown characteristics of liquids. The basis of research has almost always been an experiment using the most modern techniques to obtain the necessary empirical dependencies. 
Ignition of a discharge in conducting liquids. The specialists of the Institute of Pulse Processes and Technologies (IPPT) of the National Academy of Sciences of Ukraine studied the mechanisms of discharge formation in conductive liquids for a number of years. Thus, a unified approach to the description of fast and slow spark discharges in condensed media as phase transition waves is proposed in [14]. In [15], the results of an experimental study of the effect of high hydrostatic pressure (up to $50 \mathrm{MPa}$ ) and temperature (up to $373 \mathrm{~K}$ ) on the stage of formation of the discharge channel in the liquid and the channel stage of the discharge are presented. On the basis of these experimental data, the value of the discharge ignition voltage for water gaps from 30 to $40 \mathrm{~mm}$ is estimated by the empirical formula [15]:

$$
\begin{gathered}
U_{z}=32.9 \cdot P_{g s}^{n} \cdot\left(r_{e l} / \sigma_{0}\right)^{0.45}, \\
n=\left\{\begin{aligned}
0.1-0.12 ; & \sigma_{0}=(0.5-0.1) S / m \\
0.12-0.13 ; & \sigma_{0}=(0.1-0.03) S / m
\end{aligned}\right.
\end{gathered}
$$

where $U_{z}$ is the value of ignition voltage of the discharge, $\mathrm{kV} ; P_{g s}$ is the hydrostatic pressure, $\mathrm{Pa} ; \sigma_{0}$ is the specific electrical conductivity of aqueous electrolyte, $\mathrm{S} / \mathrm{m} ; r_{e l}$ is the radius of curvature of the rod electrode, $\mathrm{m}$.

A theoretical description of the initial stage of discharge in a conducting liquid, based on the hypothesis of the development of instabilities in its volume under the action of an electric field, is presented in [16]. The mathematical model included a system of differential equations describing the development of overheating instability, taking into account electrohydrodynamic phenomena and stabilizing heat transfer factors. The possible role of electroconvective instability in the process of germination of the breakdown branch was noted. The results of calculating the time constant of the development of the overheating instability for the spherical geometry of the electrode system were compared with the duration of the pre-leader stage of the discharge, measured experimentally with a high-speed photograph of the pre-breakdown stage of the discharge of a high-voltage capacitor on a water gap with synchronous oscillography of its electrical characteristics. Comparison of the results of calculation and experiment confirmed the correctness of the theory proposed.

The development of the theory of breakdown of conducting liquids is presented in [2, 17]. It was suggested that the threshold of ignition of the discharge in the conducting liquid would be determined by conditions ensuring the independence of the discharge in the resulting gas-vapor cavern. The ignition pattern was as follows. The gas-vapor cavity is formed at the electrode with the maximum field strength, as a result of the continuous heating of the liquid it increases in its size $d$. The growth of the cavity is accompanied by an increase in the applied voltage $U(d)$, the value of which is determined, among other things, by the potential difference between the electrodes. The breakdown of the cavity is possible when the breakdown voltage and the gap size of the critical values are reached, which can be estimated by the Paschen formula:

$$
U(d)=U_{c r}(p \cdot d),
$$

where $p$ is the gas pressure in bubble.

The critical values of voltage and diameter were calculated for a system of spherical concentric electrodes with neglect of the inhomogeneity of the field in the cavity. The results of the calculations were compared with the experimental data. The experiment was carried out on the electrode system «point - plane», and the rod protruding from under the insulating tip in the shape of a hemisphere. The experimental research circuit provided a practically rectangular voltage pulse in the stage of ignition of the discharge. The experiment was carried out in water with specific conductivity $\left(10^{-1}-10^{-3}\right) \mathrm{S} / \mathrm{m}$ at atmospheric hydrostatic pressure. Comparison of the calculated and experimental values of the ignition voltage showed good convergence in the range of the radius of the electrode-point of $(0.5-5.0) \mathrm{mm}$ and the interelectrode gap of $(60-100) \mathrm{mm}$.

In accordance with the model given in [18], the ignition voltage $U_{z}$ should be determined as the maximum of two quantities:

$$
U_{z}=\max \left(U_{t h r}, U_{c r}\right),
$$

where $U_{t h r}$ is the threshold (minimum) voltage, at which it is possible to develop an overheating instability; $U_{c r}$ is the critical ionization voltage of the gas in the bubbles formed in the heating zones, which leads to the breakdown of the bubble and the subsequent formation of a plasma branch of the breakdown.

The threshold for the development of an overheating instability is determined by the energy capacity of the source and is ensured by maintaining a constant voltage in the interelectrode gap. In the case where the voltage source is a charged capacitor bank, the threshold voltage is determined according to the expression

$$
U_{t h r}=\left(\frac{\rho \cdot c_{p} \cdot r_{e l}^{2}}{\alpha \cdot \sigma_{0} \cdot R \cdot C}\right),
$$

where $\rho$ is the liquid density, $\mathrm{kg} / \mathrm{m}^{3} ; c_{p}$ is the specific heat of the liquid, $\mathrm{J} /(\mathrm{kg} \cdot \mathrm{K}) ; \sigma_{0}$ is the liquid conductivity, $\mathrm{S} / \mathrm{m}$; $\alpha$ is the temperature coefficient of fluid electrical conductivity, $\mathrm{K}^{-1} ; R$ is the interelectrode gap resistance, $\Omega ; C$ is the capacitor bank capacitance, $\mathrm{F} ; r_{e l}$ is the anode radius, $\mathrm{m}$.

For the electrode system rod - plane, resistance of the interelectrode gap can be calculated from expression (7) using the design scheme shown in Fig. 2, in which the electrode system is modeled by concentric hemispheres [2].

$$
R=\frac{1}{2 \cdot \pi \cdot \sigma_{0}} \cdot\left(\frac{1}{r_{1}}-\frac{1}{r_{2}}\right),
$$

The critical voltage $U_{c r}$ is defined as the breakdown voltage of a bubble of diameter $d_{c r}$ appearing in the zones of maximum liquid heating. According to [2], for the electrode system shown in Fig. 2, the critical breakdown voltage of a gas bubble can be determined from expression 


$$
U_{c r}=\frac{B \cdot p_{0} \cdot d_{c r}}{c+\ln \left(p_{0} \cdot d_{c r}\right)} \cdot\left[1-\frac{1}{h-1} \cdot\left(\frac{h}{1+\frac{d_{c r}}{r_{1}}}-1\right)\right]^{-1},
$$

where $B, c$ are the empirical constants that depend on the composition of the gas inside the bubble (for example, for water vapor at $E / p=120-800(\mathrm{~V} \cdot \mathrm{m}) / \mathrm{N}$ constants $B=$ $290, c=0.3-0.6) ; p_{0}$ is the normal atmospheric pressure, $p_{0} \approx 10^{5} \mathrm{~Pa} ; h=r_{2} / r_{1} ; d_{c r}$ is the critical (minimal) size of the bubble at which its breakdown occurs determined according to (9):

$$
d \cdot\left[c+\ln \left(p_{0} \cdot d\right)-1\right]=r_{1} .
$$

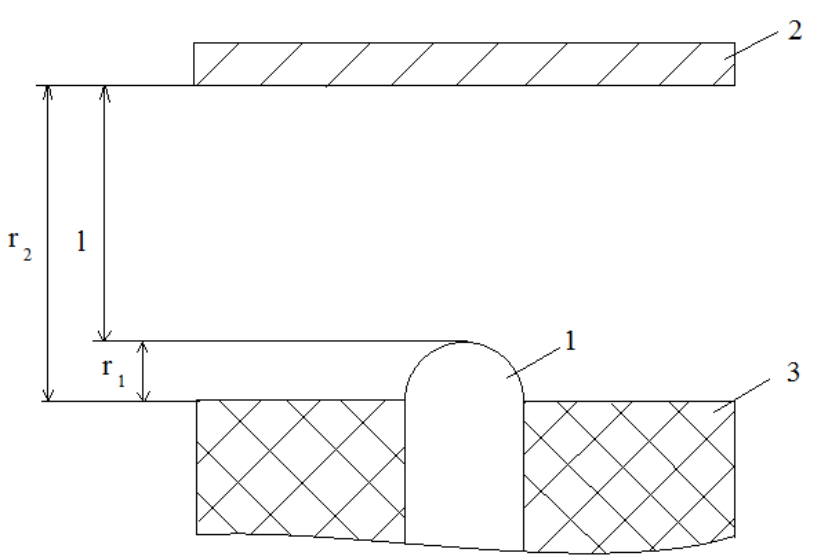

Fig. 2. The design scheme for calculation of the resistance of the gap in the electrode system rod - plane:

1 - electrode-anode (rod); 2 - electrode-cathode (plane);

3 - insulator; $l$ is the length of the interelectrode gap, m;

$$
r_{2}=l+r_{1}
$$

The calculation according to formula (8) assumes the following assumptions:

- the field inside the bubble is uniform;

- the pressure inside the bubble is equal to atmospheric pressure;

- the voltage $U(d)$ applied to the bubble is defined as the potential difference between the surface of the electrode-anode surface and the equipotential surface lagging behind it at a distance $d$;

- the distortions introduced by the bubble into the field distribution in the near-electrode region are not taken into account;

- the breakdown voltage of a bubble is determined by the Paschen similarity law.

The presented bubble model makes it possible to estimate the voltage of ignition of an electric discharge in water under normal atmospheric conditions.

Justification of the bubble discharge model based on the results of oscillography of its electrical characteristics. The physical essence of the bubble model is well analyzed when processing oscillograms of the threshold discharge modes in the water electrolyte with increased hydrostatic pressure (Fig. 3). In these modes, ignition of the discharge (luminescence) near the anode can be observed, but the streamer either does not reach the opposite electrode-cathode (Fig. 3,a), or the residual voltage on the capacitor at the beginning of the channel stage is so small that the current of the active stage of discharge is comparable with pre-breakdown currents (Fig. 3,b). Oscillograms were obtained on a laboratory bench, which makes it possible to simulate a high-voltage breakdown of a water gap under conditions of high hydrostatic pressure [19].

As can be seen from Fig. 3,a, the moment of operation of the photodiode sensor installed at a distance of $60 \mathrm{~mm}$ opposite the discharge channel to record the start of the luminescence, coincides with the characteristic curve of the current curve in the stage of discharge formation. For a qualitative analysis of the physical processes occurring at this stage of the discharge, the temporal dependences of the change in the resistance of the water gap in the electrode system (the ratio of the voltage across the gap to the current in it) were constructed. The dependencies are shown in Fig. 4. They correspond to the results of processing the oscillograms shown in Fig. 3.

Analysis of the data in Fig. 4 showed that the stage of formation of an electrical discharge in a liquid can be divided into a number of time phases.

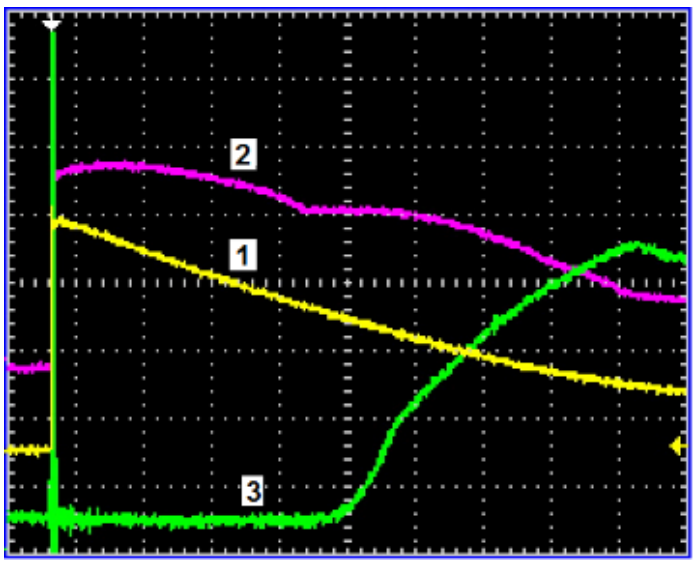

$a$

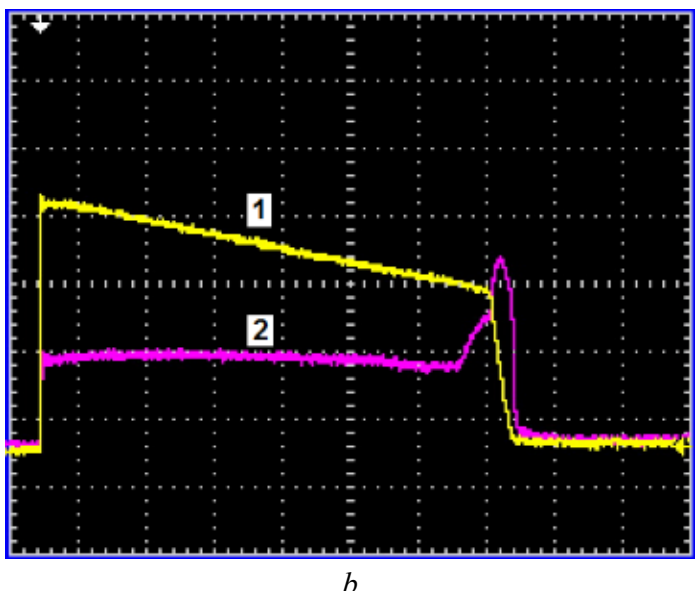

Fig. 3. The oscillograms of the threshold conditions for the electrical discharge of capacitance $C=2.47 \mathrm{uF}$ charged to voltage $U_{0}$ in an electrode system «point-plane» with a tip-anode radius $r_{e l}=1.5 \mathrm{~mm}$ and a length of the interelectrode gap $l=24 \mathrm{~mm}$ filled with an aqueous electrolyte with specific electrical conductivity $\sigma_{0}=0.2 \mathrm{~S} / \mathrm{m}$ at hydrostatic pressure $P_{g s}=10 \mathrm{MPa}: 1$ - voltage on the discharge gap; 2 - discharge current; 3 - signal of the photodiode sensor recording the luminescence near the anode; $a-U_{0}=17 \mathrm{kV} ; b-U_{0}=18.5 \mathrm{kV}$ 


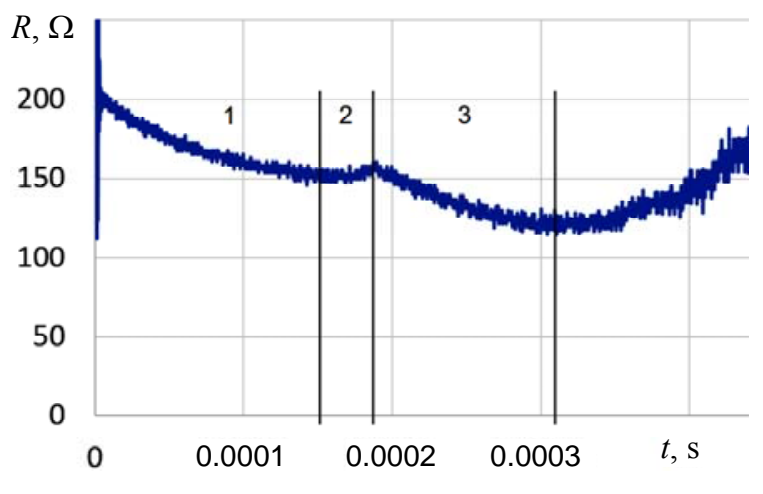

$a$

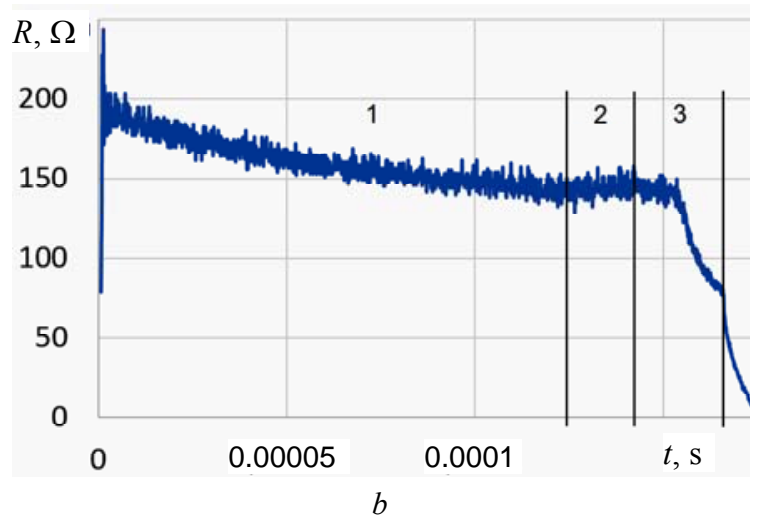

Fig. 4. The change in the resistance of the water gap calculated from the oscillograms of Fig. 3: $a-U_{0}=17 \mathrm{kV} ; b-U_{0}=18.5 \mathrm{kV}$

When the voltage is applied to the interelectrode gap in the aqueous electrolyte, pre-breakdown currents begin to flow through it. Under their action, Joule heating occurs, which is accompanied by an increase in the temperature of the electrolyte and a decrease in the active resistance of the gap in phase 1.

At the boundary of phases 1 and 2 , the resistance stabilizes with its subsequent growth in phase 2 . We assume that this change is caused by the onset of the formation of gas bubbles near the electrode-cathode. As a result, the surface area of the cathode contacting the electrolyte decreases, and the current density and temperature of the contact boundary continue to increase.

At the boundary of phases 2 and 3, the resistance again begins to decrease. We believe that at this point in time the size of the gas bubble reaches a critical value at which the residual voltage applied to the electrode system contributes to the breakdown of the bubble to form a streamer. It should be noted that at a relatively small hydrostatic pressure, the liquid is already saturated with gas inclusions, therefore the duration of phases 1 and 2 in this case is much less than at elevated pressure, which has been repeatedly confirmed by experiment. The growth of the streamer (or streamer system) leads to a decrease in resistance due to a reduction in the distance between its head and the cathode, as well as a further increase in the temperature of the electrolyte. The phase of growth of streamers can be terminated by attenuation (Fig. 4,a), followed by the restoration of the gap resistance, or by the cathode achievement by a streamer, by forming a channel of low conductivity with the dissipation of energy remaining in the energy storage device in the active stage of the discharge and a sharp decrease in resistance (Fig. 4,b).

\section{Conclusions.}

1. A review and analysis of modern concepts of prebreakdown processes in a high-voltage electric discharge in a liquid are carried out, which showed that the «bubble» model of discharge ignition in a liquid is applicable at an electric field strength $(36-180) \mathrm{kV} / \mathrm{cm}$.

2 . Based on the results of experimental studies of the electrical discharge characteristics in the aqueous electrolyte at increased hydrostatic pressure and the minimum voltage providing ignition of the discharge, the bubble model of the stage of its high-voltage breakdown formation was further developed. A qualitative description of the three phases of the stage of formation of a plasma channel in a liquid electrolyte is proposed.

3. Further development of the method for calculating the pre-breakdown characteristics of an electric discharge in a liquid on the basis of a bubble model can determine ways to increase the efficiency of a number of highvoltage electrical discharge devices.

\section{REFERENCES}

1. Gulyi G.A. Osnovy razriadnoimpul'snykh tekhnologii [Basics of discharge impulse technologies]. Kiev, Naukova Dumka Publ., 1990. 208 p. (Rus).

2. Krivitskii E.V. Dinamika elektrovzryva $v$ zhidkosti [Dynamics of electric explosion in a liquid]. Kiev, Naukova Dumka Publ., 1986. 208 p. (Rus).

3. Ushakov V.Ia. Physics of breakdown of liquid dielectrics. Bulletin of the Tomsk Polytechnic University, 2004, vol.307, no.2, pp. 80-87. (Rus).

4. Kuzhekin I.P. Investigation of the breakdown of a liquid in an inhomogeneous field with rectangular wave stresses. Technical Physics, 1966, vol.36, no.12, pp. 2125-2130. (Rus).

5. Wang Y., Liao D., Zhang W., Sun H. A COMSOL modeling of the pre-breakdown heating phase in the electro-thermal breakdown of conductive water. 3rd International Conference on Materials Engineering, Manufacturing Technology and Control (ICMEMTC 2016), 2016, pp. 704-707. doi: 10.2991/icmemtc-16.2016.141.

6. Bragg J.K., Sharbouqh A.H., Crowe R.W. Cathode effects in the Dielectric Breakdown of Liquids. Journal of Applied Physicsys, 1954, vol.25, no.3, pp. 382-391. doi: 10.1063/1.1721645.

7. Seepersad Y., Fridman A., Dobrynin D. Anode Initiated Impulse Breakdown in Water: the Dependence on Pulse Rise Time For Nanosecond and Sub-Nanosecond Pulses and Initiation Mechanism Based on Electrostriction. Journal of Physics D: Applied Physics, 2015, vol.48, no.42, p. 424012. doi: 10.1088/0022-3727/48/42/424012.

8. Sun A., Zhuang J., Huo C. Formation mechanism of streamer discharges in liquids: a review. High Voltage, 2016, vol.1, no.2, pp. 74-80. doi: 10.1049/hve.2016.0016.

9. Yan D., Bian D., Zhao J., Niu S. Study of the Electrical Characteristics, Shock-Wave Pressure Characteristics, and Attenuation Law Based on Pulse Discharge in Water. Shock and Vibration, 2016, vol.2016, pp. 1-11. doi: 10.1155/2016/6412309.

10. Ianshin E.V., Ovchinnikov I.T., Vershinin Iu.N. Mechanism of pulsed electric water breakdown. Reports of AS of the USSR, 1974, vol.214, no.6, pp. 1303-1306. (Rus).

11. Ushakov V.Ia., Klimkin V.F., Korobeinikov S.M., Lopatin V.V. Proboi zhidkostei pri impul'snom napriazhenii [Breakdown of liquids under impulse voltage]. Tomsk, NTL Publ., 2005. 488 p. (Rus). 
12. Clements J.S., Sato M., Davis R.N. Preliminary investigation of prebreakdown phenomena and chemical reaction using a paused high-voltage discharge in water. IEEE Transactions on Industry Applications, 1987, vol.IA-23, no.2, pp. 224-235. doi: 10.1109/TIA.1987.4504897.

13. Fujita H., Kanazawa S., Ohtani K., Komiya A., Kaneko T., Sato T. Initiation process and propagation mechanism of positive streamer discharge in water. Journal of Applied Physics, 2014, vol.116, no.21, p. 213301. doi: 10.1063/1.4902862.

14. Kuskova N.I. Spark discharges in condensed media. Technical Physics, 2001, vol.46, no.2, pp. 182-185. doi: 10.1134/1.1349273.

15. Poklonov S.G. Vysokovol'tnye elektrorazriadnye pogruzhnye ustanovki so stabilizatsiei elektrogidroimpul'snogo vozdeistviia. Avtoref. diss. kand. tekhn. nauk [High-voltage electric discharge submersible devices with stabilization of electrohydropulse impact. Abstracts of cand. tech. sci. diss.]. Kiev, 2004. 18 p. (Rus).

16. Zhekul V.G., Rakovskii G.B. To the theory of the formation of an electrical discharge in a conducting liquid. Technical Physics, 1983, vol.53, no.1, pp. 8-14. (Rus).

17. Rakovskii G.B., Khainatskii S.A, Zhekul V.G. To calculation of the discharge ignition voltage in conducting liquids. Technical Physics, 1984, vol.54, no.2, pp. 368-370. (Rus).

18. Rakovskii G.B. Peregrevnaia neustoichivost' $v$ nachal'noi stadii elektricheskogo razriada $v$ provodiashchei zhidkosti. Av-toref. diss. kand. fiz.-mat. nauk [Overheating instability in the initial stage of an electrical discharge in a conducting fluid. Abstracts of cand. phys.-math. sci. diss.]. Leningrad, 1984. 23 p. (Rus).

19. Smirnov A.P., Zhekul V.G., Mel'kher Iu.I., Taftai E.I., Khvoshchan O.V., Shvets I.S. Experimental study of pressure waves generated by an electric explosion in a closed volume of a liquid. Elektronnaya obrabotka materialov, vol.53, no.4, pp. 47-52. (Rus). doi: 10.5281/zenodo.1053757

Received 05.04.2018

V.G. Zhekul ${ }^{1}$, Candidate of Technical Science, Senior Research Scientist,

O.V. Khvoshchan ${ }^{1}$, Candidate of Technical Science, Senior Research Scientist,

O.P. Smirnov ${ }^{1}$, Candidate of Technical Science, Senior

Research Scientist,

E.I. Taftaj ${ }^{1}$, Research Scientist,

I.S. Shvets ${ }^{1}$, Candidate of Physics and Mathematics Sciences,

Leading Research Scientist,

${ }^{1}$ Institute of Pulse Processes and Technologies (IPPT) of NAS of Ukraine,

43-A, Bohoyavlensky Ave., Mykolayiv, 54018, Ukraine, phone +380 512224113 ,

e-mail: Smirnovap1978@gmail.com, Khvoshchan@gmail.com

How to cite this article:

Zhekul V.G., Khvoshchan O.V., Smirnov O.P., Taftaj E.I., Shvets I.S. Analysis and development of the bubble model of the formation stage of high-voltage breakdown of the water gap. Electrical engineering \& electromechanics, 2018, no.4, pp. 63-69. doi: 10.20998/2074-272X.2018.4.11. 